\title{
Coherent Acoustic Phonons in Colloidal Semiconductor Nanocrystal Superlattices
}

Caroline L. Poyser, Thomas Czerniuk, Andrey V. Akimov, Benjamin T. Diroll, E. Ashley

Gaulding, Alexey S. Salasyuk, Anthony J. Kent, Dmitri R. Yakovlev, Manfred Bayer, and

Christopher B. Murray

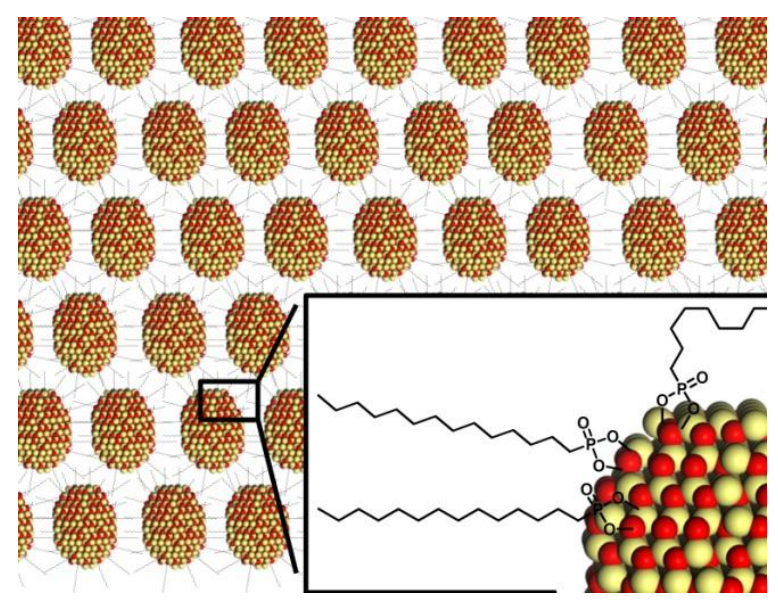

Figure S1. Schematic of supra-crystal of colloidal nanocrystals. The CdSe nanocrystals are terminated on the surface with tetradecylphosphonic acid. Image is not to scale. 


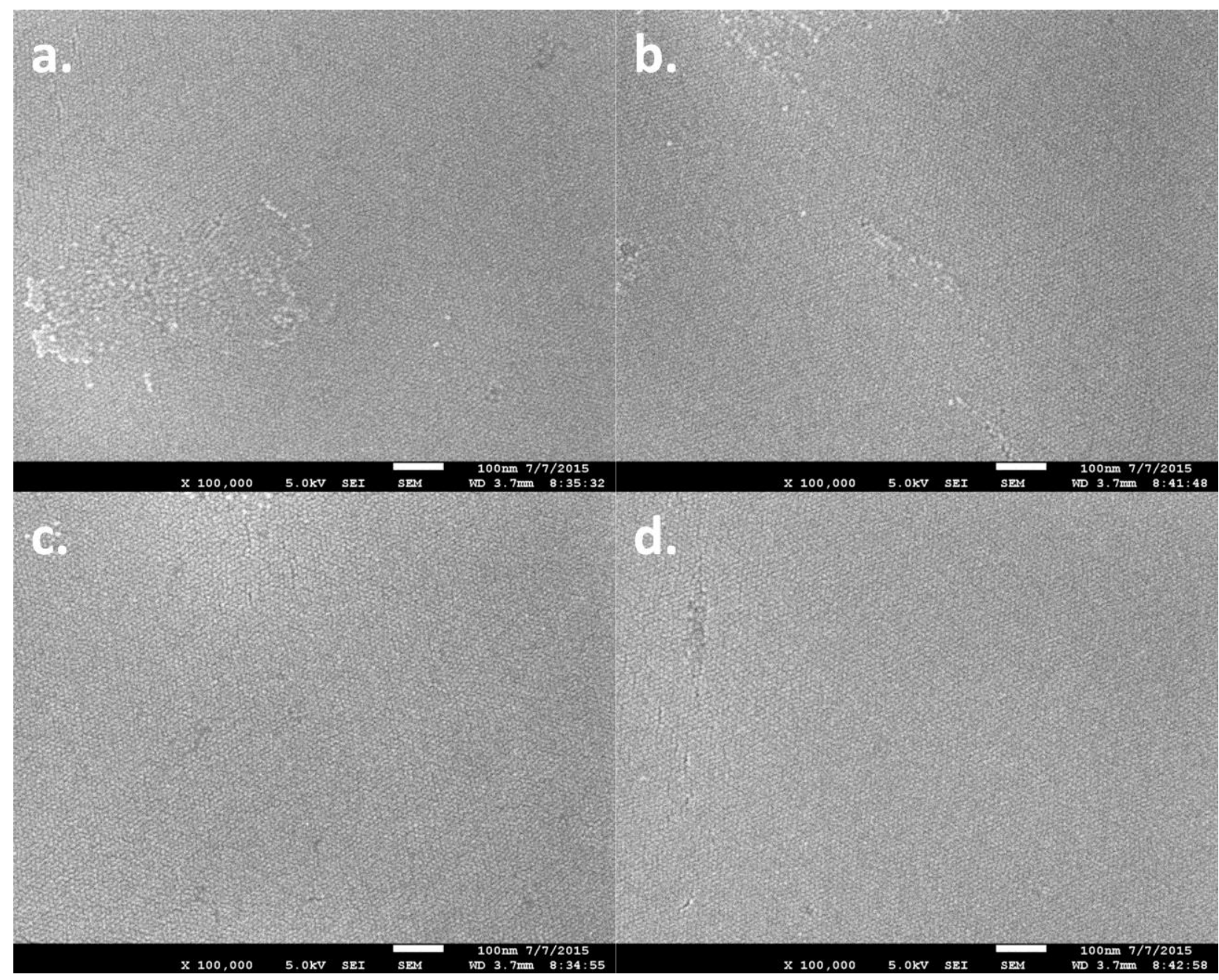

Figure S2. (a-d) SEM surveys of Sample C showing several spatially-distinct areas of the same film.

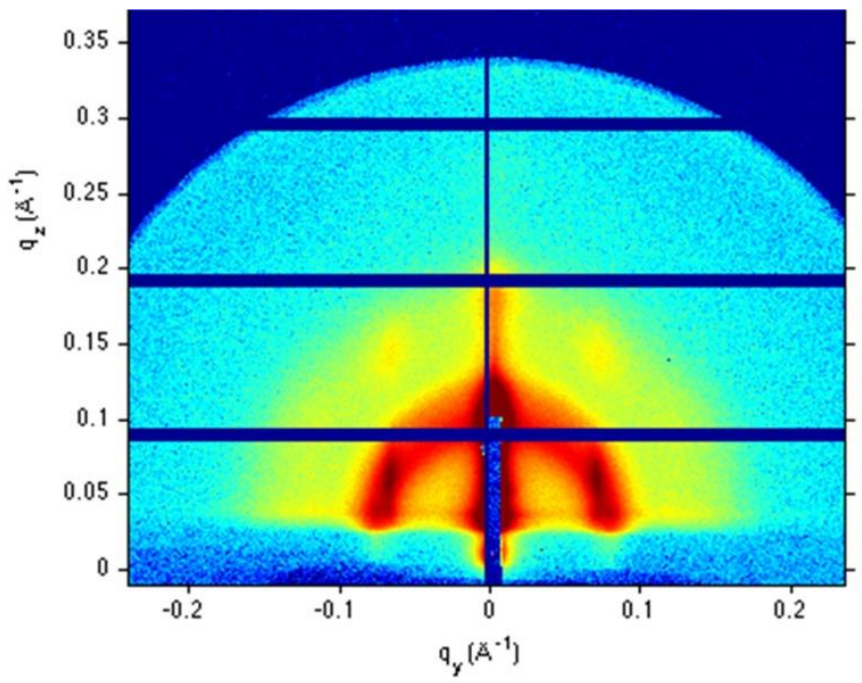

Figure S3. GISAXS detector image of Sample C. 


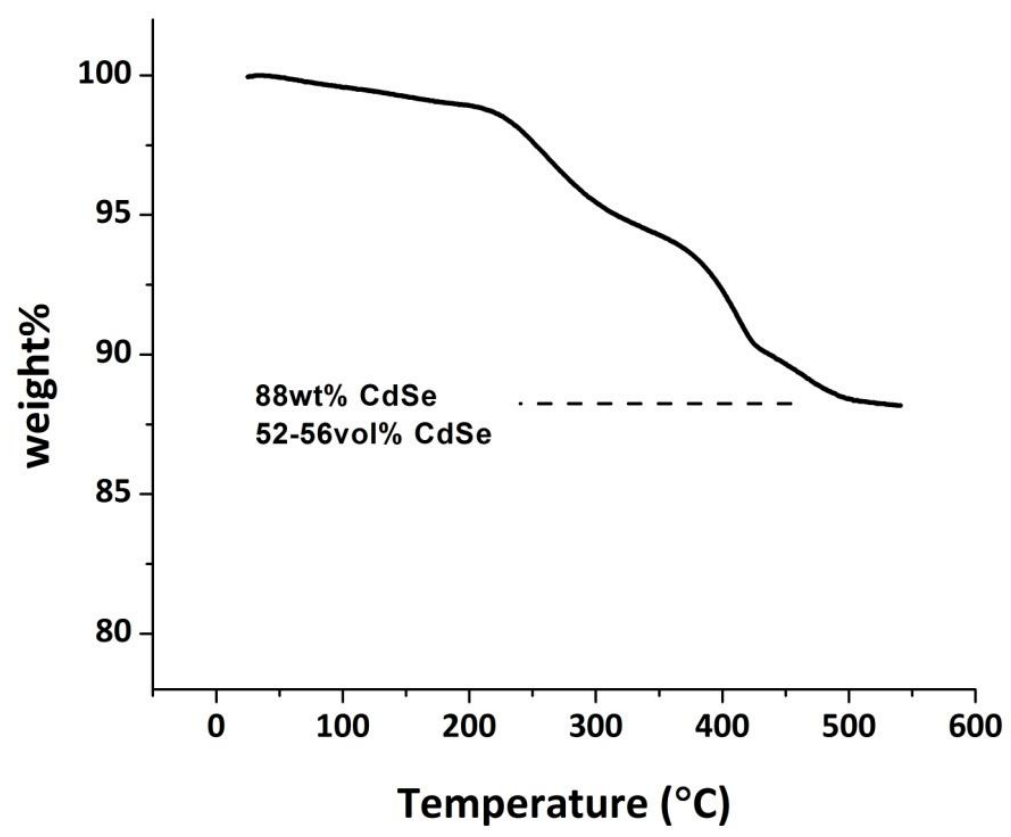

Figure S4. Thermogravimetric analysis of CdSe nanocrystal sample. Weight loss measurements were performed under air flow at $100 \mathrm{~mL} / \mathrm{min}$ from room temperature to $550{ }^{\circ} \mathrm{C}$ at a rate of 20 ${ }^{\circ} \mathrm{C} / \mathrm{min}$. The weight percent of inorganic material is calculated from the total weight loss. The volume fraction range of CdSe is calculated assuming a bulk CdSe density $\left(5.83 \mathrm{~g} / \mathrm{cm}^{3}\right)$ for $88 \%$ of the material with a range of $0.85-1.0 \mathrm{~g} / \mathrm{cm}^{3}$ for the remaining organic weight fraction. 